\title{
Composite Photographs and the Quest for Generality: Themes from Peirce and Galton
}

\author{
Chiara Ambrosio \\ Department of Science and Technology Studies \\ UCL \\ c.ambrosio@ucl.ac.uk
}

\begin{abstract}
Along with being a visual method of scientific investigation in its own right, the process of composite photography was often invoked, in the late nineteenth and early twentieth century, as a powerful philosophical metaphor. I investigate an early chapter in the life of this metaphor: its reception and use by the American philosopher, logician and scientist Charles S. Peirce. I show how Peirce's use of composite photography was rooted in his sophisticated philosophical position on the composite process itself, which had been originally developed by Sir Francis Galton in the late 1870s. I highlight substantial differences in the ways Peirce and Galton drew on the composite process to advance broader epistemological claims - especially claims concerning the nature and reliability of scientific generalisations. I argue that Peirce and Galton's respective approaches to the issue of generalisation and generality condense deeper epistemological tensions that deserve renewed philosophical consideration. I conclude by arguing that the material dimension of photography as a mode of representation in its own right, and in particular the limitations of the photographic process as an "objective" mode of representation, were ultimately of crucial importance for the ways in which Peirce adopted and articulated the metaphor of composite photography in his philosophical works.
\end{abstract}

\section{Introduction}

In "The Body and the Archive", now a classic in visual culture, Allan Sekula concludes his comparative study of the uses of photography by Alphonse Bertillon and Francis Galton with a brief remark invoking two semiotic categories originally proposed by Charles Sanders Peirce:

\footnotetext{
"The American philosopher and semiotician Charles Sanders Peirce [...] made a useful distinction between signs that referred to their objects indexically and those that operated symbolically. To the extent that photographs are "effects of the radiations from the object", they are indexical signs, as are all signs which register a physical trace. Symbols, on the other hand, signify by virtue of convention and rules" ${ }^{1}$
}

\footnotetext{
An early version of this article was presented in July 2014 at the Charles S. Peirce International Centennial Congress (University of Massachusetts, Lowell). I am grateful to the conference participants, particularly Aud Sissel Hoel, Tullio Viola, Mats Bergman, Gabriele Gava and Jaime Nubiola for their constructive comments. Vincent Colapietro provided invaluable mentoring and encouragement: hopefully this piece will serve as a first heartfelt thank you for the time he spent, in person and in writing, bringing Peirce's philosophy to life for the next generation of Peirce scholars. Joel Snyder's excellent advice, questions and thorough commentary offered plenty of food for thought, along with precious suggestions that genuinely improved the scholarly quality of
} 
Bertillon and Galton's respective approaches to photography, Sekula suggests, follow relatively well this distinction. With his extended system of catalogue cards containing information about individual characters - notoriously criminals - and by subordinating the singular image to the explicative function of language in the annotations accompanying the cards, ${ }^{2}$ Bertillon "remained wedded to an indexical order of meaning". ${ }^{3}$ Galton, on the other hand, cultivated the aspiration of producing general types - an aspiration fulfilled by his highly successful method of composite portraiture. Through composite photography, Sekula argues, Galton elevated the indexical to the symbolic: the accretion of contingent individual instances in his case turned into a quest for generalities and laws. Universal, "lawlike" traits, in Galton's "unwitting caricature of inductive reasoning" ${ }^{4}$ could be visually inferred, and were indeed visually supported by the evidence of common features exhibited by the composite photographs themselves.

Sekula's brief reference to Peirce's semiotic categories has passed largely unnoticed in the literature. Readers acquainted with the history, theory, and critical studies of photography possibly just glossed over it as another instance of the practice, distinctive of the late 1970s and 1980s, of acknowledging Peirce in analyses of photography that invoked the notion of indexicality as the mechanism governing photographic images and their evidential role in broader visual arguments. Yet, the reference here is not only (partially) appropriate, or at least loosely pertinent, from a conceptual point of view - it is also historically relevant, in that it discloses an angle on the history of composite photography that has remained so far unexplored.

Sekula correctly remarks that Peirce was a contemporary of Galton and Bertillon. While the latter does not seem to feature in Peirce's works and writings, various aspects of Galton's photographic method attracted Peirce's attention from very early on and left a long-standing mark on his own subsequent work. Galton's seminal publication on composite photography, entitled "Composite Portraits, Made by Combining Those of Many Different Persons into a Single Resultant Figure", was first presented at the Anthropological Institute of Great Britain in 1877. It first appeared in a published form in Nature in 1878. It was subsequently published in the Popular Science Monthly in the same year, and it also featured in the Anthropological Institute's journal in $1879 .{ }^{5}$ In those

this piece. My colleagues at the Department of Science and Technology Studies (UCL) were kind enough to discuss an early draft of this paper and put up, once more, with my obsession with Peirce. For this, and for their friendly advice and criticism, I am extremely grateful. The staff at the Houghton Library and UCL Special Collections provided prompt help with the reproduction of the images and manuscripts. Until the very last version of this paper, Niall Le Mage kept asking "So, what exactly is a percept?". Alas, behind every philosopher there is usually a much sharper critical conscience, one direct enough to ask the really important questions.

${ }^{1}$ Allan Sekula, "The Body and the Archive", October no. 39(1986):3-64, p. 55.

2 Bertillon and his method, known as "Bertillonage" have been the object of a current revival in history of science and history of art. Along with Sekula, "The Body and the Archive", see also Alex Csiszar, "Bibliography as Anthropometry: Dreaming Scientific Order at the fin de siècle", Library Trends, vol. 62, no. 2 (2013):442-455; Josh Ellenbogen, "Camera and Mind", Representations, 2008, vol. 101, no. 1 (2008):86-115; and Josh Ellenbogen, Reasoned and Unreasoned Images: The Photography of Bertillon, Galton, Marey, (Pennsylvania State, 2012).

3 Allan Sekula, "The Body and the Archive", p. 55.

${ }^{4}$ Allan Sekula, "The Body and the Archive", p. 55.

${ }^{5}$ Francis Galton, "Composite Portraits made by combining those of many different persons into a single figure", Nature vol. 18 (1878): 97-100; Francis Galton, “Composite Portraits made by combining those of many 
very years Peirce was busy working for the US Geodetic and Coast Survey (where he was employed from 1860 to 1891), publishing his only book, the Photometric Researches, ${ }^{6}$ writing for The Nation (to which he contributed over 300 articles throughout his life) and simultaneously developing his philosophy, logic and mathematics. As an active scientific writer and a practicing scientist, Peirce was well acquainted with Galton's work more broadly, and not just with his experiments with composite photography. Galton's contributions to statistics naturally appealed to Peirce's mathematical mind. His study of English Men of Science ${ }^{7}$ prompted Peirce to take up a similar task, which culminated in a series of extended notes and writings on nineteenth century men of science. ${ }^{8}$ From the $1890 \mathrm{~s}$ onward - over a decade after Galton announced his new photographic method - Peirce adopted and began using in a surprisingly systematic way the metaphor of composite photography to articulate some of the pillars of his philosophy.

Why was the metaphor compelling for Peirce, and what is the value of spelling out the reasons of his particular predilection for it? Sekula seems to suggest that composite photographs, at least for Galton, fulfilled the dream of a quintessentially empiricist quest for generality. My account tries to spell out what "generality" meant in Galton and Peirce's respective approaches, and how the material dimension of composite photography mediated their quests. What I aim to show is that their very different relations to the medium of photography ultimately resulted in different articulations of the epistemic reliability they placed on the photographic process more broadly. In a time of proliferating analogies between camera and mind, Galton and Peirce's accounts of the epistemic lessons that could be drawn from composite photography stand out as indicative of two divergent and equally instructive examples of the attitude that scientists displayed toward the philosophical applicability of this relatively new medium. ${ }^{9}$

In "Family Resemblances and Family Trees", Carlo Ginzburg describes the reception of Galton's composite photography as a compelling case of a cognitive metaphor that takes on "a life of its own". ${ }^{10}$ While fully acknowledging that the original aims of Galton's method were ultimately to improve social control, ${ }^{11}$ Ginzburg insightfully suggests that the subsequent adoption of the

different persons into a single figure", The Popular Science Monthly, vol. 13 (August 1978): 460-469; Francis Galton, "Composite Portraits made by combining those of many different persons into a single figure", The Journal of the Anthropological Institute of Great Britain and Ireland, vol. 8 (1879): 132-144. Throughout the text, I will refer to the first publication of Galton's article in Nature.

${ }^{6}$ Charles S. Peirce, Photometric Researches (Leipzig, 1878).

${ }^{7}$ Francis Galton, English Men of Science: Their Nature and Nurture, (London, 1874).

${ }^{8} \mathrm{~A}$ full version of the main text on nineteenth century men of science by Peirce is reprinted in Philip P. Wiener (ed.) Charles S. Peirce, Selected Writings (New York, 1958): 265-274. The piece was originally published in 1900 as part of Peirce's Annual Report of the Smithsonian Institution.

${ }^{9}$ For an insightful account of the vicissitudes of the metaphor of the mind as a camera in the history of philosophy, see Aud Sissel Hoel, "Lines of Sight: Peirce on Diagrammatic Abstraction", in Das Bildnerische Denken: Charles S. Peirce, ed. F. Engel, M. Quesner, and T. Viola (Berlin, 2012), pp. 253-271. For a discussion of how it impacted nineteenth century photography see especially Ellenbogen, "Camera and Mind".

${ }^{10}$ Carlo Ginzburg, "Family Resemblance and Family Trees: Two Cognitive Metaphors", Critical Inquiry vol. 30, no.3 (2004): 537-556, pp. 546-7.

${ }^{11}$ It is relatively well known that Galton's early experiments with the portraits were made possible because he had access, through the Director of Prisons Edmond du Cane, to photographs of prisoners. See Francis Galton, Memoirs of my Life (London, 1908), pp. 259-61, and D.W. Forrest, Francis Galton: The Life and Work of a Victorian Genius (London, 1974), p. 138. But as Sekula correctly suggests, Galton's photographic work was only 
metaphor was motivated by distinctively epistemological aims: "All the readers I mentioned disregarded the aim of Galton's experiments in photography...[C]omposite portraits made them think. Galton's images acquired a life of their own, opening up new spaces of reflection" ${ }^{12}$ The aim of my discussion is to explore a chapter in the early life of this metaphor, one in which the material nature of a particular visual artefact gradually begins to get detached from its initial context of production, but at the same time still maintains some crucial conceptual and material connections with it. In Peirce's particular case, I argue that composite photography became a guide to articulate conceptual tools that were then used to investigate the nature and functioning of photographic displays and the reliability of the photographic process more broadly. Specifically, what I hope to show is that Peirce used the metaphor of composite photography as a way of undermining some of the assumptions implicitly built into a common sense view of photography as mere mechanical reproducibility, and that he did so in light of his profoundly critical understanding of the photographic process itself.

I will begin with a brief description of Galton's articulation of the composite process and with some historical details about Peirce's own understanding of some of the implications of Galton's work. I will then consider the broader impact of the metaphor on Peirce's philosophical account of perception and the formation of ideas and judgments, which rely heavily on analogies with composite photographs. I will conclude by arguing that the material dimension of photography as a mode of representation in its own right, and in particular the limitations of the photographic process as an "objective" mode of representation, were of crucial importance for the ways in which Peirce adopted and used the metaphor. It is this sophisticated position on the material aspect of photography that, in my view, directed Peirce toward a critique of mere mechanical reproducibility, a critique that ultimately led him to reframe the "mind as a camera" metaphor and reconceptualise it in completely new terms.

\section{Galton on Composite Photographs}

"[T]he photographic process...enables us to obtain with mechanical precision a generalised picture; one that represents no man in particular, but portrays an imaginary figure possessing the average features of any given group of men. These ideal faces have a surprising air of reality. Nobody who glanced at one of them for the first time would doubt its being the likeness of a living person. Yet, as I have said, it is no such thing; it is the portrait of a type and not of an individual" ${ }^{13}$

\footnotetext{
tangentially related to criminology per se - it was instead part of a broader enterprise ultimately aimed at using statistics (and eugenics, his own brainchild) for the purpose of the "betterment" of the British race. See Sekula, "The Body and the Archive", p. 18. Thus, the composite process was used not just for individuating "criminal types", but also for investigating family traits, proclivity to illness (particularly in women), breeding in general (including the breeding of animals) and, later, to isolate typical racial features.

${ }^{12}$ Ginzburg "Family Resemblance and Family Trees", p. 547-7. "The readers" mentioned by Ginzburg include Wittgenstein and Freud, who both adopted the metaphor of composite photography without embracing its social implications.

${ }^{13}$ Galton, “Composite Portraits", p. 97.
} 
Ambrosio/ Composite Photographs and the Quest for Generality Critical Inquiry, 42 (Spring 2016), 547-579

Please cite from the published version

Thus Galton began his description of the photographic process he had developed in the previous years, and that he baptised as "composite photography" (fig. 1).

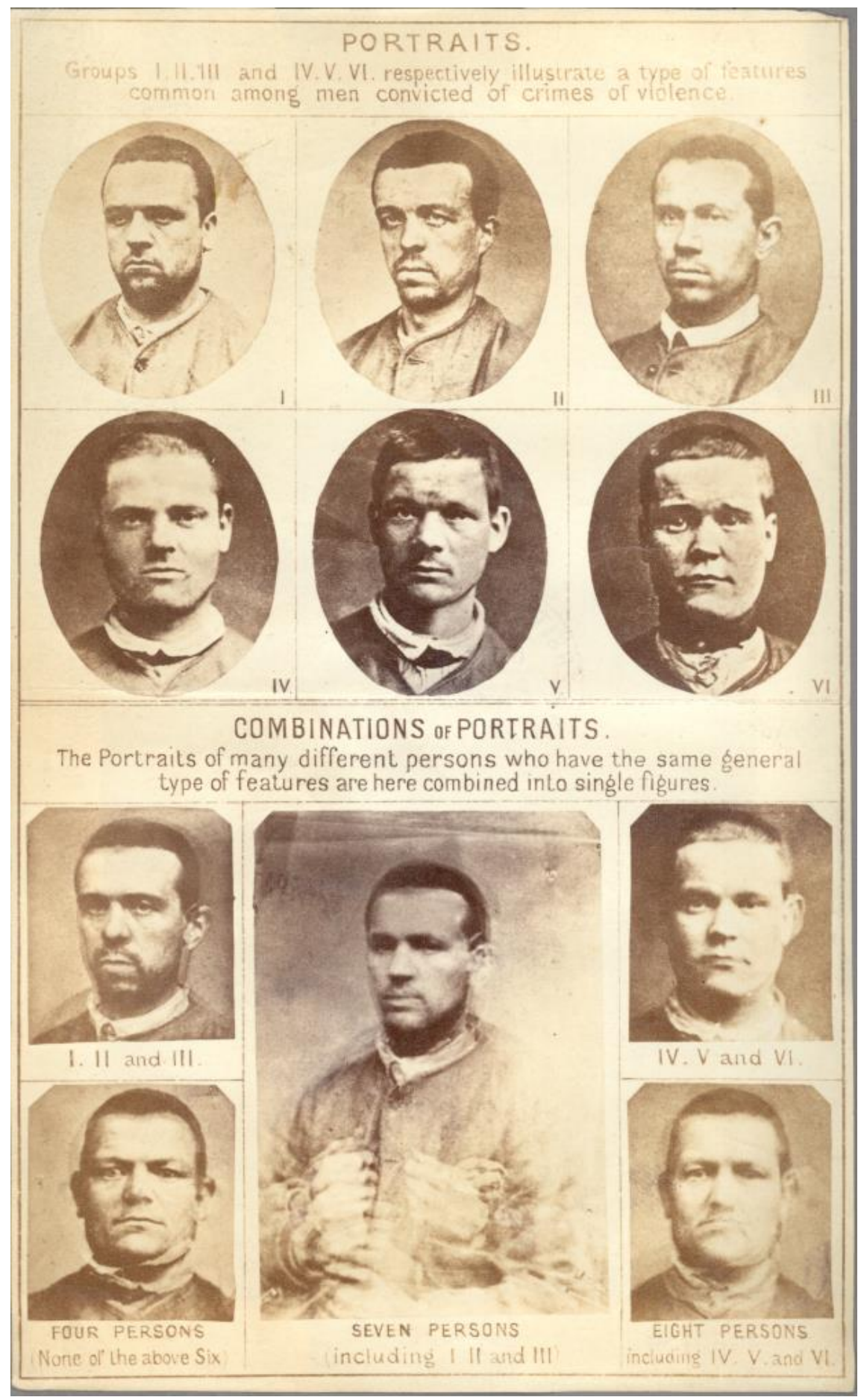

Fig. 1. Francis Galton, Composite Portraits of Criminal Types, 1877. Albumen Silver Print from Glass Negative. The Galton Archive, University College London Special Collections.

That the idea of producing composite portraits was somehow in the air at the time is acknowledged by Galton himself. He credits his own initial thoughts on the subject to a conversation he had with Herbert Spencer, in which Spencer himself suggested that composite images could be obtained by 
reducing drawings to the same scale, superimposing them, and holding them against a source of light. ${ }^{14}$ Galton's own cousin, Charles Darwin, had shared with him a letter from a "Mr A.L. Austin of New Zealand", who claimed to have developed a process for superimposing two photographic portraits by placing them in a stereoscope. The result, Austin wrote in his letter, was particularly impressive in the case of ladies' portraits, for it produced "in every instance, a decided improvement in beauty". ${ }^{15}$ Galton had tried Austin's stereoscopic method, however his ultimate aim was to combine more than just two portraits. ${ }^{16}$ Composite photography fulfilled Galton's dream of a truly pictorial statistics, one that could be supported by the photographic method in achieving "real generalizations". As he explains in a subsequent article, aptly entitled "On Generic Images":

"Composite pictures are...much more than averages; they are rather the equivalents of those large statistical tables whose totals, divided by the number of cases and entered on the bottom line, are the averages. They are real generalizations, because they include the whole of the material under consideration. The blur of their outlines, which is never great in truly generic composites, except in unimportant details, measures the tendency of individuals to deviate from the central type" ${ }^{17}$

Galton's idea of "real generalizations" becomes clearer when placed against the background of the concrete details of his method. Composite portraits are obtained by the successive exposure of a number of portraits to a camera holding a single plate. Galton suggests that exposure times should be worked out fractionally: the exposure time of a single portrait in the sample should be the inverse of the total number of portraits in the sample itself. Thus, for a total exposure time of eighty seconds and a sample of eight portraits, each individual in the sample should be exposed for ten seconds. Of course, part of the success of the process depended on the preliminary preparation of the portraits themselves, which should all be of the same size and which should all be aligned "in such a way that the eyes of all the portraits shall be as nearly as possible superimposed". ${ }^{18}$ (See fig 2)

\footnotetext{
${ }^{14}$ Galton, "Composite Portraits", p.97. The practice of creating composite drawings and caricatures has a much longer history, which relates, among other things, to visual and specifically printing cultures of science. See for example Jim Secord, "Scrapbook Science: Composite Caricatures in late Georgian England", in Figuring it Out: Science, Gender and Visual Culture, ed. A. B. Shteir and B. Lightman (Hanover, 2006), pp. 164-191.

${ }^{15}$ Cited in Galton, "Composite Portraits", p. 98.

${ }^{16}$ See Karl Pearson, The Life, Letters and Labours of Sir Francis Galton. Vol. 2: "Researches and Middle Life". (Cambridge, 1924), p. 284, and Forrest, "Francis Galton”, p. 138.

${ }^{17}$ Francis Galton, “Generic Images", Proceedings of the Royal Institution vol. 9 (1879):161-170, p. 166 (emphasis mine).

${ }^{18}$ Galton, "Composite Portraits", p. 97.
} 


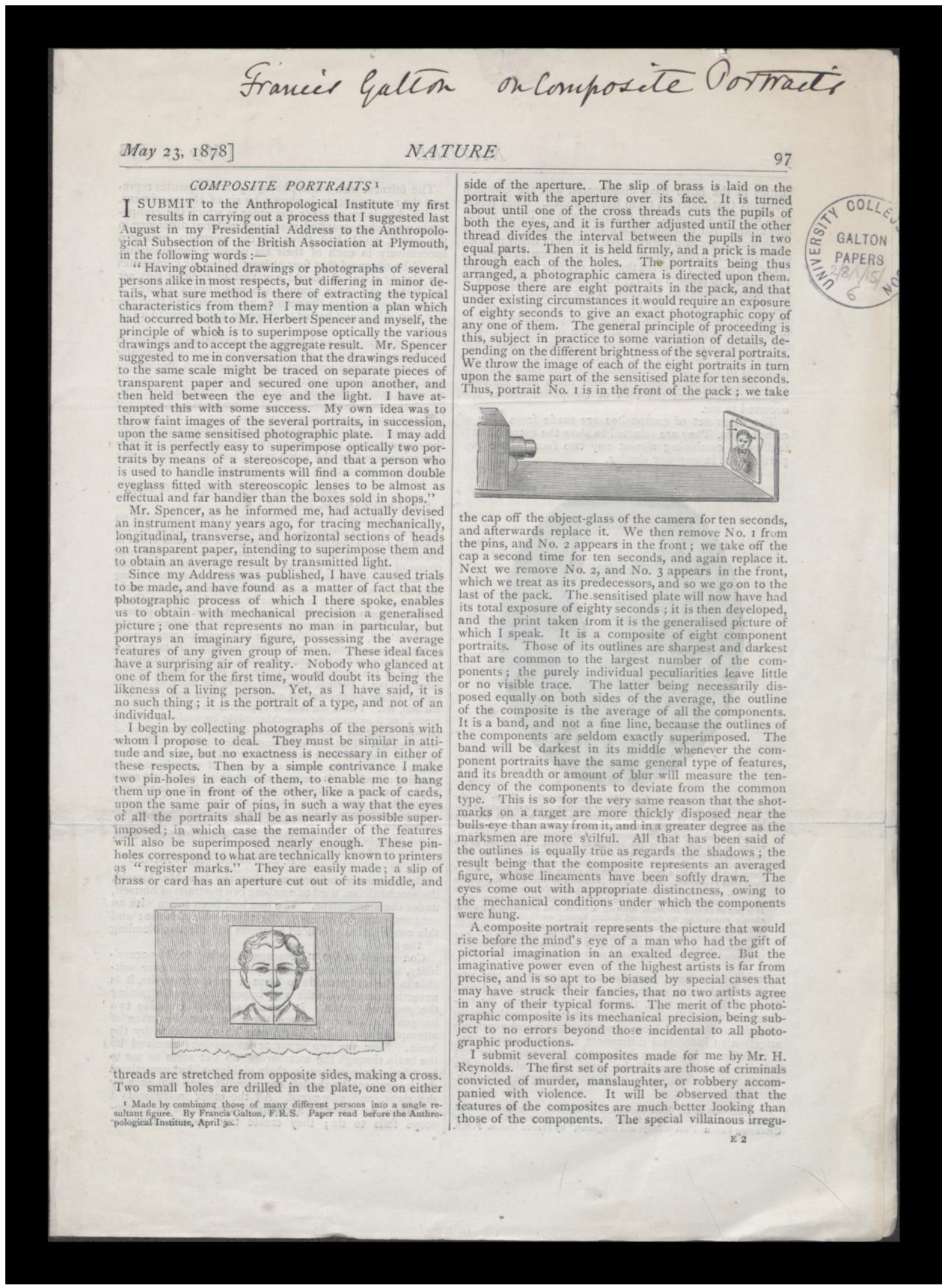

Fig. 2. Francis Galton, illustrations from “Composite Portraits”, Nature 18 (1878), 97. 
Thus conceived, the process allowed the selection of features that were "common", or belonging to the general type behind all the portraits in the sample, while blurring away merely "accidental" information or unimportant details that did not strictly pertain to the general features being measured through the composite process itself. It is in this sense that Galton saw his portraits as "real generalizations": composite photography ultimately deferred the epistemic burden of generalising from the observer to the camera. This approach betrays Galton's ambivalent attitude toward the reliability of what should be considered as genuine empirical evidence more broadly. On one hand, he was quite fond of drawing parallels between composite photographs and ideas more generally. So, for instance, in Inquiries into Human Faculty, he described the results of his method as follows:

"The ideal faces thus obtained by the method of composite portraiture appear to have a great deal in common with...so called abstract ideas" ${ }^{19}$

Just like abstract ideas, composite photographs are generalizations from data accessible through experience, and just like ideas the photographs capture ideal types rather than particular instances. In this particular respect, Galton's approach to photography seemed to revolve around the hope that the composite process would in principle guarantee some criterion of public testability for the very process underpinning all generalisations. The blurred lines in the periphery of the portraits and the "essential features" at the centre were somehow visible to everyone, and the simple act of inspecting a composite portrait would allow any viewer to access, and repeat, the very process of drawing generalisations from a number of individual instances. Thus construed, composite photography aspired to the status of an ideal form of empiricism, one in which observable evidence gathered through the photographic process answered the very question of what makes (inductive) generalisations reliable.

On the other hand, however, Galton was haunted from the outset by a far more pressing concern. Abstract ideas, thus construed, seemed just a philosophically appealing but humanly unattainable chimera. The limits of empiricism still persisted, and depended directly on the limits of human faculties such as memory and pictorial imagination. This concern is articulated in all its forcefulness quite early on in Galton's first article on composite photography:

\footnotetext{
${ }^{19}$ Francis Galton, Inquiries Into Human Faculty and Its Development (London, 1883), p. 183. Philosophical discussions of the process of abstraction here described by Galton have a long and vexed history. A key point of reference, known to Galton, was John Locke's theory of abstraction and concept formation, famously discussed in book III of An Essay Concerning Human Understanding. There, Locke proposes that general ideas and general names are arrived at through a process of negative selection, whereby individual features of a certain range of particulars are progressively left out until only what is shared among those particulars remains. Thus, in infancy "the ideas of the persons that children encounter are, like the persons themselves, only particular". However, Locke argues, "As they get older and meet more people, infants notice that many other things in the world resemble-in shape and in other ways - their father and mother and other people they have been used to; and they form an idea that applies equally to all those many particular people, associating this idea with the name 'man'. That is how they come to have a general name and a general idea. In doing this, they had of Nurse and Mamma, Peter and James, Mary and Jane, whatever is unique to each, and retain only what is common to them all". John Locke, An Essay Concerning Human Understanding (1690), ed. Peter Nidditch (Oxford: 1975), Book III (Words), Chapter iii (General Terms), §7. For a discussion on how Peirce addresses these issues in his account of perception see Hoel, "Lines of Sight", pp. 255-258.
} 


\begin{abstract}
"A composite portrait represents the picture that would rise before the mind's eye of a man who had the gift of pictorial imagination in an exalted degree. But the imaginative power even of the highest artist is far from precise, and is so apt to be biassed by special cases that may have struck their fancies, that no two artists agree in any of their typical forms. The merit of the photographic composite is its mechanical precision, being subject to no errors beyond those incidental to all photographic productions". ${ }^{20}$
\end{abstract}

Our human capacity to generalise, Galton remarks, is extremely limited. On purely psychological grounds, what we call "ideas" or even "generalisations" might be subject to the same variability that is inherent in all things human. There is no certainty, after all, that properties we may subjectively take as essential are in fact merely accidental. Not even the best artists, who are supposedly acquainted with the practice of producing visual generalisations, are endowed with the capacity to generalise without interfering with the material content of their generalisations. This is where photography becomes an indispensable aid to achieve the kind of ideal empiricism Galton aspired to: photography guarantees mechanical precision just where human faculties fail. By blurring the idiosyncratic and retaining in view only the typical, composite photography not only lends visual evidence to the material content of our generalisations: it shows that "pure" generalisations, independent of the differences and peculiarities of particular individuals arriving at those generalisations, are a desirable empirical aspiration in the first place.

In their recent work on the history of objectivity, Lorraine Daston and Peter Galison describe Galton as a hybrid character at the crossroads between the epistemic virtues of truth-to-nature and mechanical objectivity. ${ }^{21}$ Galton's aspiration to produce general types, Daston and Galison argue, is in line with the eighteenth century epistemic drive toward idealisation, pursued by removing the idiosyncratic and the particular in the quest for generality. But while eighteenth century truth-tonature required the wilful intervention of the scientist in achieving this goal, Galton's quest for ideal types was performed following the canons of self-discipline imposed by a new kind of mechanical ideal of objectivity. Indeed, Daston and Galison place the birth of the very notion of objectivity as "mechanical reproducibility", with all its connotations of increased precision and increased reliability, almost concomitantly with the emergence and diffusion of a broad array of recording instruments in the mid-nineteenth century. Photography occupied a privileged place in the construction of the rhetoric of self-restraint that characterised this new approach to objectivity, for a simple and yet compelling reason:

"One type of mechanical image, the photograph, became the emblem for all aspects of noninterventionist objectivity...This was not because the photograph was more obviously faithful to nature than handmade images - many paintings bore a closer resemblance to their subject matter than early photographs, if only because they used color - but because the camera apparently eliminated human agency". ${ }^{22}$

\footnotetext{
${ }^{20}$ Galton, "Composite Portraits", p. 97.

${ }^{21}$ Lorraine Daston and Peter Galison, Objectivity (New York, 2007), pp. 168ff.

${ }^{22}$ Daston and Galison, Objectivity, p. 187.
} 
Galton's emphasis on the reliability of mechanical precision betrays his commitment to a noninterventionist view of objectivity, one in which the limitations of human knowledge become a reason to defer agency to the camera and to the photographic process entirely. Despite the fact that Galton did not specifically frame his work in terms of objectivity in his writings, his emphasis on the limitations of empiricism and on the necessity of a mediating instrument to safeguard both generality and precision reflects the broader ethos of self-restraint that animated other advocates of the value of mechanical reproducibility in his time. What Daston and Galison leave partly in the background, however, is the fact that Galton's enthusiasm for the photographic process was driven primarily by a philosophical dilemma concerning the limitations of the human powers of generalisation, and more broadly the nature of abstract ideas.

Indeed, in the years that followed his early work with composite photographs, Galton set out to investigate the nature of mental imagery and its limitations more broadly. Starting roughly from 1879 he carried out a study of over 100 men, mostly scientists, whose visual memory and general capacity of producing mental images were surveyed by means of a questionnaire. ${ }^{23}$ The study, now a classic in the history of psychology, was cited at length in William James' 1890 Principles of Psychology, and praised as having "made an era in descriptive psychology" ${ }^{24}$ Incidentally, Galton's study is discussed by James precisely in a section of the Principles of Psychology that surveys how individual differences affect the human faculty of imagination. "There are imaginations, not 'the Imagination'", ${ }^{25}$ James states just before introducing Galton. Citing other key proponents of psychological studies of individual differences such as Gustav Fechner, James seems to endorse the view that one possible way of drawing generalisations about such differences in mental imagery is "to work up the subject statistically", ${ }^{26}$ and praises Galton's method as the first important experimental step in that direction. But while James saw the instability of individual differences in imagery as a fertile terrain for further psychological and experimental investigation, Galton seemed to approach the problem as further evidence of the need of a mediating instrument to tame their inherent variability.

In his extensive study of Galton's work on mental imagery, David Burbridge states that there is no clarity around the reasons that compelled Galton to take up the subject in the first instance, but that this work could be easily interpreted as a "natural progression" of studies he carried out in those very years. ${ }^{27}$ Indeed, Burbridge's references mainly comprise Galton's publications on composite photography. Thus, it is reasonable to conjecture that composite photography opened up a whole set of new questions for Galton - questions that he set out to investigate empirically through the very statistical methods he was most acquainted with, and which he had developed throughout his life. The results of his questionnaire provided an answer to the thorny issue of the kind of mental imagery scientists were capable of, and Galton's conclusion was that scientists were

\footnotetext{
${ }^{23}$ The questionnaire was included, in an edited version, as an appendix to Galton's Inquiries into Human Faculties. The full text of Galton's questionnaire is reproduced in David Burbridge, "Galton 100: An Exploration of Francis Galton's Imagery Studies". The British Journal for the History of Science, vol. 27 (1994): 443-463, pp. 448-449 (Table 1).

${ }^{24}$ William James, The Principles of Psychology (Cambridge, Mass., [1890] 1983), p. 696.

25 James, The Principles of Psychology, p. 696.

${ }^{26}$ James, The Principles of Psychology, p. 696.

${ }^{27}$ Burbridge, “Galton $100 "$, p. 445.
} 
not, ultimately, distinguished by their enhanced powers of visualisation: "Scientific men, as a class, have feeble powers of mental representation". ${ }^{28}$ Leaving aside the disputes around the details of Galton's statistical method in arriving at these conclusions, ${ }^{29}$ what is interesting is that the study is a clear attempt at proving the fundamental flaws of the very faculty that composite photography aimed to support, and for which it seemed to provide new epistemological reliability. The photographic process, for Galton, filled in a precise epistemological gap, the existence of which was eventually documented experimentally in his subsequent studies on mental imagery.

\section{Peirce on Composite Photographs}

A convinced Kantian for most of his life (albeit not an uncritical one), Peirce subscribed to the epistemological view that the limits of our knowledge are also its conditions of possibility. Thus, where Galton saw a fundamental flaw in the human capacity to generalise and represent - a flaw that the process of composite photography was supposed to correct - Peirce saw an opportunity. By transforming Galton's method into a conceptual metaphor, Peirce's aim was to devise an exploratory tool to understand the nature of ideas.

Composite photographs appear as a recurrent theme in Peirce's philosophical writings in the 1890s, and they are specifically used to cast light on his account of ideas. A thorough evaluation of the complexities of Peirce's work on the subject is well beyond the scope of this discussion, ${ }^{30}$ however a few important remarks are here in place. Like Galton, Peirce thought that ideas bear the hallmark of generality. But contrary to Galton, he firmly believed that the capacity of arriving at reliable, yet fallible, generalisations fell fully within the remit of our cognitive powers. Thus his use of the metaphor does not draw on the function of the composite process or the camera as vehicles of self-restraint or self-discipline: on the contrary, Peirce shifts the epistemic burden of the process of generalising back to the faculty of judgment. One of the earlier instances in which Peirce compares ideas to composite photographs appears in the context of his 1895 Short Logic, ${ }^{31}$ where he discusses precisely the issue of how ideas partake of the content of judgments or assertions. A judgment or assertion, Peirce states, consist in the application of a general concept, or a "mental icon" (or indeed an idea) to a particular case or circumstance. For instance, he claims, applying the concept of dishonesty to someone (and here the content of the example has a distinctive Galtonian flavour), amounts to having "in mind something like a composite photograph of all the persons I have known and read of who have had that character". ${ }^{32}$ Thus, Peirce incisively continues, "at the instant I make the discovery concerning that person, who is distinguished from others for me by certain indications,

\footnotetext{
${ }^{28}$ Francis Galton, “Statistics of Mental Imagery”, Mind vol. 5 (1880): 301-318, p. 304.

${ }^{29}$ These are thoroughly surveyed in Burbridge, "Galton 100", pp. 457ff.

${ }^{30}$ In what follows, I will build on the work of Christopher Hookway, who has discussed in detail the relations between composite photographs, ideas and Kantian schematism in Christopher Hookway, "'A Sort of Composite Photograph': Pragmatism, Ideas and Schematism". The Philosophical Transactions of the Peirce Society, vol. 38, no. 1 / 2 (2002): 29-45.

${ }^{31}$ Now reprinted in The Essential Peirce: Selected Philosophical Writings, 2 vols. Ed. N. Houser and C. Kloesel eds. (vol.1) and The Peirce Edition Project (vol.2), (Bloomington, 1992/1994), 2: 11ff. References to The Essential Peirce will henceforth take the form "EP", followed by volume and page number.

32 Peirce, EP2: 19-20.
} 
upon that index, at that moment, down goes the stamp of RASCAL, to remain indefinitely". ${ }^{33}$ Asserting that someone is dishonest (or applying the predicate "rascal" to someone), Peirce explains, amounts to singling out - indexically, perhaps through a demonstrative or a proper name - a particular person and applying a general idea or predicate to them. Such a general idea, Peirce claims, takes the form of an image, or rather of "a composite photograph", of all the instances that fit into the general class subsumed under that particular predicate.

But how do we come to form that "composite photograph" in the first instance? In other passages, which clearly betray his ambivalent relationship with psychology, Peirce maps the problem more openly on the relation between ideas and perception. Peirce's theory of perception is at least as complex as his account of the formation of ideas, ${ }^{34}$ and I will only be able to sketch its general features. But the two topics are profoundly interconnected, and at least a few general details are needed here, in order to grasp Peirce's broader claims. More importantly, in connecting ideas and perception, Peirce provided an answer to the very problem Galton struggled with when addressing the issue of generality and ideas. Interestingly, one of the (several) places in which Peirce discusses his theory of perception is in a 1901 review of the Grammar of Science, written by Galton's protégé and future biographer Karl Pearson. ${ }^{35}$

One of Peirce's criticisms is directed to the claim, advanced particularly in chapter II of Pearson's Grammar of Science, that first impressions serve as the starting point for reasoning. Peirce accuses Pearson of falling into "the too common error of confounding logic with psychology" ${ }^{36}$ That sense impressions may be the starting point of how we individually acquire knowledge, Peirce claims, is "a correct statement of a conclusion of psychology" ${ }^{37}$ But to place it, as Pearson does, at the basis of the "Facts of Science" (which is also the title of Pearson's entire chapter), is for Peirce a conceptual mistake. Pearson's "facts" are for Peirce the end point of the logical operations of reasoning. Reasoning belongs to the realm of logic (which Peirce construes very broadly and equates with semiotics), and as such has an altogether different starting point:

"[T]he starting point of all our reasoning is not in those sense impressions, but in our percepts. When we first wake up to the fact that we are thinking beings and can exercise some control over our reasoning, we have to set out upon our intellectual travels from the home where we already find ourselves. Now this home is the parish of percepts". ${ }^{38}$

Two points in Peirce's criticism of Pearson are important here. First, logic, or valid reasoning more broadly, is controlled reasoning: it is reasoning that still remains eminently fallible, but it is so exactly because it appeals to the control of our judgment. Second, the starting point of reasoning, thus construed, is not what psychologists define as sense impressions, but what Peirce defines as "the

\footnotetext{
${ }^{33}$ Peirce, EP2: 20 (emphasis in the original).

${ }^{34}$ A classic in the study of Peirce's account of perception is Richard Bernstein "Peirce's Theory of Perception", in Studies in the Philosophy of Charles S. Peirce, Second Series, ed. E. Moore and R. Robin (Amherst, 1964), pp. 165-189.

${ }_{35}$ Peirce, EP2:57-66.

${ }^{36}$ Peirce, EP2:61.

${ }^{37}$ Peirce, EP2:61.

${ }^{38}$ Peirce, EP2:62.
} 
parish of percepts" ${ }^{39}$ Percepts for Peirce have no generality, and they do not appeal (as yet) to reason: they are "our logical initial data" and "their home is not in our skulls... but out in the open". ${ }^{40}$ At the same time, Peirce claims, percepts are subject to psychological (in Peirce's terms "psychical") operations of three continuous kinds: qualities of feeling, reactions, and generalising elements. Peirce illustrates this point with the example of an inkstand, and (rather unsurprisingly, at this stage) composite photographs come back into his discussion:

"I see an inkstand on the table: that is a percept. Moving my head, I see a different percept of my inkstand. It coalesces with the other. What I call the inkstand is a generalised percept, a quasi-inference from percepts, perhaps I might say a composite photograph of percepts. In this psychical product is involved an element of resistance to me, which I am obscurely conscious of from the first". ${ }^{41}$

What Peirce is trying to articulate here is an anti-intuitionist and (simultaneously) an anticonstructivist view of perception. On one hand, he claims, no intuition is involved in knowledge or cognition. We possess the faculty of generalising, by creating a composite photograph of percepts and arrive at a "generalised" percept, but this faculty is not of the kind of clear and distinct ideas. ${ }^{42}$ On the other hand, however, "generalised" percepts are not just constructions - they are hypotheses that can be somehow tested empirically. And the test will tell us that if we are dreaming of seeing a fairy in place of the inkstand, the inkstand will "resist" until we come up with a new hypothesis about the general percept we see in front of us. "Hypothesis" is indeed Peirce's own term, and it is directly related to the fallibility of our "quasi-inferences from percepts". His discussion of the inkstand continues as follows:

"Subsequently, when I accept the hypothesis of an inward subject for my thoughts, I yield to that consciousness of resistance and admit the inkstand to the standing of an external object. Still later, I may call this in question. But as soon as I do that, I find that the inkstand appears there in spite of $\mathrm{me}^{\prime \prime}{ }^{43}$

Peirce then says that it is possible to come up with a variety of methods of testing the "inkstand hypothesis". We might appeal to external witnesses. We might even resort to a camera to record the situation; and yet the inkstand will still be there, opposing its resistance to any attempt to prove that it is not. It is this resistance that makes the inkstand real, and at the same time it is this resistance that lends generality to our recognition of a particular cluster of percepts as "an inkstand".

\footnotetext{
39 In a paper entitled "Telepathy and Perception" Peirce connects his choice of "percepts" to its original etymology in res percepta. See Peirce, Charles S. 1931-8/1958. Collected Papers of Charles Peirce ed. C. Hartshorne, A. Burks and P. Weiss, 8 vols. (Cambridge, Mass., 1931-8/1958), vol. 7, paragraph 634. References to the Collected papers will henceforth take the form " $C P$ ", followed by volume and paragraph number.

40 Peirce, EP2:62.

${ }^{41}$ Peirce, EP2:62.

${ }^{42}$ Peirce developed his critique of Cartesian intuitionism early on in his philosophy. His 1868 essays "Questions Concerning Certain Faculties Claimed for Men" and "Some Consequences of Four Incapacities" (Peirce, EP1, chapters 2 and 3 ) are indeed referred to as the "anti-Cartesian essays" by Peirce scholars, and advance a range of anti-intuitionist arguments that Peirce retained and developed further for the rest of his life.

${ }^{43}$ Peirce, EP2:62.
} 
Let us pause for a moment and think about how Peirce's account compares with Galton's so far. On one hand, Galton came to a standstill because he decided to remain anchored to a crude form of empiricism, one that still held that the common sense view of science as proceeding from sense impressions to generalisation had some mileage. What Galton did, or attempted to do, was strengthen the epistemic reliability of this common sense picture by replacing the empiricist's "tabula rasa" with the photographic plate, and let "real generalisations" speak for themselves. But this led him into the blind alley of "blind-sight" ${ }^{44}$ : knowledge without a knower, in the form of mechanical reproducibility, was the only way of validating the purity of his composite, ideal types. Peirce, on the other hand, pursued a different agenda. Solving the problem of generalization, for him, required an exploration of the commonalities, and boundaries, between logic and psychology. Composite photographs became useful not because "the mind worked as a camera" in a naïve empiricist sense, but because the metaphor itself showed just the kind of control (performed by the faculty of judgment) the mind has over the process of generalisation. I will return to this important point in the next section.

Peirce's account of perception goes well beyond the simplified picture I presented above. A missing tile in the mosaic is what exactly makes "generalised percepts" meaningful in the first place. An essential stage in perception is first and foremost the recognition of a specific object - say an inkstand, to continue with Peirce's example - as an inkstand. Recall the fact that for Peirce percepts are singular - they simply "are" without any appeal to reason. An act of mediation is needed to turn the percept into a meaningful object of perception. Here Peirce appeals to the difference between percepts and perceptual judgments: "it is the perceptual judgment that tells us what we so perceive". ${ }^{45}$ Perceptual judgments have a representative function, and as such they have generality. ${ }^{46}$ From a logical point of view, Peirce explains, perceptual judgments consist in applying a predicate to a percept, and it is this operation that makes percepts "subjects of belief or disbelief". ${ }^{47}$ Saying - to use another of Peirce's examples - "I see a yellow chair in front of me", amounts to applying the predicate yellow to the present percept of a chair. For Peirce, however, this is different from applying a general category of "yellowness" to a particular object. This would in fact still leave unexplained where we get the general category of "yellowness" from - which incidentally is the whole point of resorting to the metaphor of composite photographs for an answer. It is here that Peirce's theory of perception becomes particularly interesting, as it explicitly advocates an act of comparison:

"[T]he perceptual judgment 'this chair appears yellow' has vaguely in mind a whole lot of yellow things, of which some have been seen, and no end of others may be or

\footnotetext{
${ }^{44}$ Daston and Galison, Objectivity, p. 17.

${ }^{45}$ Peirce, CP 7.643.

${ }^{46}$ Peirce offers an extensive discussion of his theory of perception in "Telepathy and Perception" (c1903), partly published in CP 7. A thorough discussion of the manuscript, specifically in relation to Peirce's account of perception, is in Hoel, "Lines of Sight". Hoel offers a diagrammatic and differential account of mediation in perception, which convincingly explains - among other things - why Peirce's use of the metaphor of composite photographs goes well beyond Galton's appeal to "real generalisations".

${ }^{47}$ Peirce, CP 7.626.
} 
might be seen; and what it means to say is 'take any yellow thing you like, and you will find, on comparing it with this chair, that they agree pretty well in colour". ${ }^{48}$

Perceptual judgments are essentially dynamic in nature - and once again the metaphor of composite photography intervenes to account for the dynamic and iconic components of perception. Peirce states that the process, thus construed, "explicitly invites the exercise of freedom of choice on the part of the interpreter": perceiving amounts to actively comparing the yellow of the chair with "a sort of composite photograph of all the yellows that have been seen". ${ }^{49}$ This particular case shows another essential respect in which Peirce's understanding of composite photography is radically different from Galton's. Galton's composite photographs are static: they are presentations of ideal types, whose generality is validated by the reliability of the mechanical process that served for their generation. Peirce's composites, on the other hand, are inherently dynamic: they have an experiential basis (some of the yellow shades to which we compare the colour of our chair may have been seen), but they also have some kind of predictive power (the composite photograph will allow us to recognise other shades of yellow as "yellow", and apply them to other percepts).

Christopher Hookway has related this aspect of Peirce's articulation of composite photographs to his equally profound commitment to one of the pillars of Kantian philosophy: the doctrine of Schematism. ${ }^{50}$ Introducing the concept of schema, Hookway argues, is the most convincing way to explain the kind of generality that Peirce attributes to ideas, and their functioning as "mental icons". Schematism still remains an extremely puzzling and nebulous chapter (or rather an "afterthought", as Peirce describes it) of Kant's Critique of Pure Reason. Here I am not so much concerned with the technical or exegetic details of Kant's own definition of schema, but rather with the reception and use of this philosophical construct by Peirce. In general terms, Kant appeals to schemata in trying to explain how concepts (which are the products of the faculty of understanding) are applied to the empirical world and to its objects, which we experience in space and time. The role of schemata in imagination, for Kant, provides the crucial connection. Schemata are indeed rules, methods, or procedures produced by the faculty of imagination that allow us to anticipate experience (and in doing so, to make sense of it conceptually). Schemata, in other words, mediate between the faculty of understanding and experience, and they do so by virtue of their generative character.

It is easy to see how the idea might have appealed to Peirce. His account of perception relates precisely to the problem of the interplay between our cognitive powers and their relation to experience, and Schematism here seems to provide an answer. Even more importantly, Schematism provides an answer that calls directly into question the iconic features of cognition: the schema is a mental icon, at the same time particular and general, whose primary character is to disclose new relations in experience. For Peirce this is made forcefully clear by examining icons in relation to the dynamic characterisation of composite photographs I provided above. Rather than a static generalisation obtained by the mere synthesis of individual instances, for Peirce a composite

\footnotetext{
${ }^{48}$ Peirce, CP 7.632.

${ }^{49}$ Peirce, CP 7.634.

${ }^{50}$ Hookway, "A Sort of Composite Photograph".
} 
"generates a sequence of shades", ${ }^{51}$ with a particular spatial and temporal configuration. As Hookway suggests, Peirce's approach to composite photography is in this particular respect exactly the reverse as Galton's original conception: “perhaps we use composite photographs as 'templates' or stereotypes in applying concepts - or at least in applying some concepts". ${ }^{52}$ This is indeed the opposite of Galton's static characterization of "real generalisations", which seem to presuppose a straightforward (inductive) inferential path from experience to general conclusions. The very comparative element that Peirce places at the centre of the formation of fully fledged perceptual judgments renders his account of perception far more sophisticated, at the same time offering a plausible insight into the very process underpinning our capacity to generalise. Although Peirce is never clear about the relation between schemata and perceptual judgments, it seems that the generative nature of schemata provides a justification -within the remit of our cognitive capacities for how we come up with general classes (or predicates) in the first place and for how we subsume new, unseen or yet unexperienced cases under a general class.

A further comparison with Galton's approach is here appropriate. If we accept the interpretation that the generative character of composite photographs is of primary importance for Peirce, and that this generative character consists precisely in the composite providing - in the case of the predicate "yellow" - a sequence of shades that invites further comparison, then the relation we establish with what really matters in the material configuration of a composite photograph is also subject to revision. For Galton the centre of the image is the essential part of the photograph, as it is in the centre that "typical features" congregate. For Peirce, on the contrary, the interesting process happens in the periphery of the images, the areas in which shading suggests further, possibly new ways of applying the composite "template" to a new context and deriving novel relations through its application.

This seems to find an interesting resonance with the idea, fully developed by Peirce only around 1905, that a "logic of vagueness" characterises every act of predication, and is inherent in all semiotic processes, including perception. ${ }^{53}$ The application of the predicate "yellow" to a particular percept defines a general range to which the percept belongs - thus undermining its initial singularity - at the same time introducing a productive vagueness that allows both for the identification of previously experienced instances and for the recognition of new ones. This seems an intuition that Peirce develops even before his fully fledged account of vagueness of (circa) $1905^{54}$ : as early as 1903, in the very text on perception which introduces the notion of perceptual judgments, he states that "[t]he perceptual judgment 'this chair appears yellow' has vaguely in mind a whole lot of yellow things" ${ }^{55}$ In this case, the virtue of applying the predicate "yellow" consists precisely in its vague, and therefore generative, dimension.

\footnotetext{
${ }^{51}$ Hookway, "A Sort of Composite Photograph", p. 40.

52 Hookway, "A Sort of Composite Photograph", p. 32.

${ }^{53}$ I am deeply grateful to Tullio Viola for pointing out this interesting connection and for forcing me to think about it in the first place. I am especially grateful for the philosophical headaches it has caused, which are very likely to generate further work in that direction.

${ }^{54}$ See for instance Peirce, EP:2, 350ff.

${ }^{55}$ Peirce, CP 7.632 (emphasis mine).
} 
In other instances, and perhaps confusingly, Peirce says that "vagueness is the antithetical analogue of generality". ${ }^{56}$ But this antithetical relation is just what makes vagueness productive in spite of our efforts to overcome it. Peirce partly addresses this issue in a 1905 Monist article entitled "Issues of Pragmaticism", where the relation between generality and vagueness is articulated in more detail:

"[T]here are cases in which we can have an apparently definite idea of a border line between affirmation and negation. Thus a point of a surface may be in a region of that surface, or out of it, or on its boundary. This gives us an indirect and vague conception of an intermediacy between affirmation and denial in general, and consequently of an intermediate, or nascent state, between determination and indetermination. There must be a similar intermediacy between generality and vagueness". ${ }^{57}$

The very "intermediacy" stressed by Peirce between generality and vagueness might help explain at least one of the reasons why he saw the metaphor of composite photography as fruitful in the first place. Composite portraits seem to condense, pictorially, "the intermediate, or nascent state, between determination and indetermination". It is for this reason that I interpreted Peirce's account as giving renewed importance to the fuzzy boundaries of a composite portrait, rather than the congregation of "typical features" at the centre of the images. Composite photographs seem to be, in this particular respect, the materialisation of the antithetical interplay between vagueness and generality, an interplay that ultimately casts light on the meaning of "generality" that Peirce attributes to conceptual processes and functions such as perceptual judgments and ideas. In dismissing the periphery of the portraits as containing "merely" accidental features, Galton seemed to deprive his comparison between composite portraits and general ideas of its most forceful and persuasive element.

It is at this point that the cognitive metaphor of composite photographs seems to take on "a life of its own" in Peirce, and become completely detached from the initial context in which it was produced. Indeed, most current studies of Peirce's work on composite photography have a distinctively conceptual flavour - and rightly so, considering the relations that Peirce provocatively suggests with conceptual constructs such as "ideas", "schemata" and even "perceptual judgments". But it would be deeply unfair to both Peirce and Galton, as well as historically inaccurate, to assume that the twists and turns of the composite metaphor took place exclusively "in Peirce's head", or that they were exclusively the product of his conceptual and philosophical work. Peirce's metaphor has a material dimension, primarily supported by archival evidence which remains so far unpublished and which has been thoroughly neglected in the literature. It is to this neglected evidence that I would like to turn to in the next section.

\footnotetext{
${ }^{56}$ Peirce, CP 5.505. An excellent discussion of Peirce's logic of vagueness and of how it relates to some of the pillars of his philosophy is in Phyllis Chiasson, "Peirce's Logic of Vagueness", in The Commens Encyclopedia: The Digital Encyclopedia of Peirce Studies. New Edition. Ed. M. Bergman and J. Queiroz. Pub. 121220-2309a. Retrieved from http://www.commens.org/encyclopedia/article/chiasson-phyllis-peirce\%E2\%80\%99s-logicvagueness (last accessed 07/08/2014).

${ }^{57}$ Peirce, EP2: 353.
} 


\section{Composite Photography in Peirce's Manuscripts}

Peirce repeatedly proves to have been acquainted with the material process behind composite photography, and with photographic processes more broadly. While at present there is no compelling evidence of his direct experimentation with photographic processes, his writings and scientific collaborations suggest that his philosophical positions on photography were motivated by an active interest in, and solid understanding of, the photographic process itself. ${ }^{58}$ As I will show more in detail later on, Peirce's semiotic notion of indexicality, for instance, bears on a notion of instantaneous photography very much modelled on nineteenth century views of "instantaneity", while his practical understanding of composite portraiture reflects the experiments with the process carried out by his student and collaborator Joseph Jastrow. ${ }^{59}$

In what follows, I aim to show that there are textual references which further substantiate Peirce's sophisticated understanding of composite portraiture and his use of it as a conceptual metaphor. I will refer to two particular objects - a typescript and a manuscript, both undated - from the Peirce Archives held by the Houghton Library at Harvard. Both objects offer interesting evidence of Peirce's familiarity, and indeed of his opinionated understanding, of the photographic process underpinning Galton's experiments. Despite the lack of contextual information, the contents of these archival materials reveal that Peirce may have cultivated a rather persistent - albeit somewhat quiet - interest in the composite process developed by Galton.

A quick glance at the typescript (fig. 3$)^{60}$ reveals that it corresponds to the last page of the text of Galton's first article on composite photography, published in Nature in 1878. The typescript page contains a footnote with precise instructions on how to calculate the fractional exposure times, and the main content of the text explains the possible future developments of the process for the purpose of animal breeding, as well as to produce family portraits that might possibly disclose hereditary characteristics. Galton specifically invites the readers to contribute with materials that would allow him to continue his investigation:

"I have as yet had few opportunities of developing the uses of the composite photographic process, it being difficult without explanation to obtain the requisite components. Indeed, the main motive of my publishing these early results is to

\footnotetext{
${ }^{58}$ For a less tentative assessment of Peirce's involvement with photographic processes see Alexander Robins, "Peirce and Photography: Art, Semiotics and Science", The Journal of Speculative Philosophy vol. 28, no. 1 (2014), pp. 1-16. While I concur with Robins in interpreting even Peirce's most speculative allusions to photography as inextricably related to his broader work on scientific measurement, and while I strongly believe that Peirce had a sophisticated understanding of the photographic process, what I could find in the Peirce Archives is, so far, only evidence suggesting an indirect knowledge of the medium, rather than evidence of direct experimentation with it.

${ }^{59}$ The connection with Jastrow's experiments is further discussed in note 66 below.

${ }^{60}$ In what follows, I will use the conventional classification of Peirce's manuscripts as listed in Richard Robin, Annotated Catalogue of the Papers of Charles S. Peirce (Worcester, Mass., 1967). Peirce's untitled and undated typescript is classified as MS 1362.
} 
afford that explanation. I especially want sets of family photographs, all as nearly as possible of the same size and taken in the same attitude" ${ }^{61}$

Galton then proceeds to give measurements, in terms of size and even proportions of the faces captured in individual portraits, that would make for the "ideal" contribution to the prosecution of his inquiries into family portraiture. Why exactly this particular typescript page has been preserved (as opposed to the full text of Galton's article) is obviously open to speculation. The typescript is clearly marked "Nature" at the end, so it is possibly something that Peirce might have reviewed for publication or might have received from one of his correspondents. Another possibility, still entirely speculative, is that Peirce might have reviewed the text before it was re-published in the Popular Science Monthly in 1878. Interestingly enough, Galton's article appeared in the same volume in which Peirce published the sixth paper ("Induction, Deduction, Hypothesis") of his series "Illustrations on the Logic of Science", and indeed their two contributions lie side by side in the August 1878 issue of the journal.

${ }^{61}$ Peirce, MS 1362, np; this is exactly the same text as Galton, “Composite Portraits", p. 100. 
Ambrosio/ Composite Photographs and the Quest for Generality Critical Inquiry, 42 (Spring 2016), 547-579

Please cite from the published version

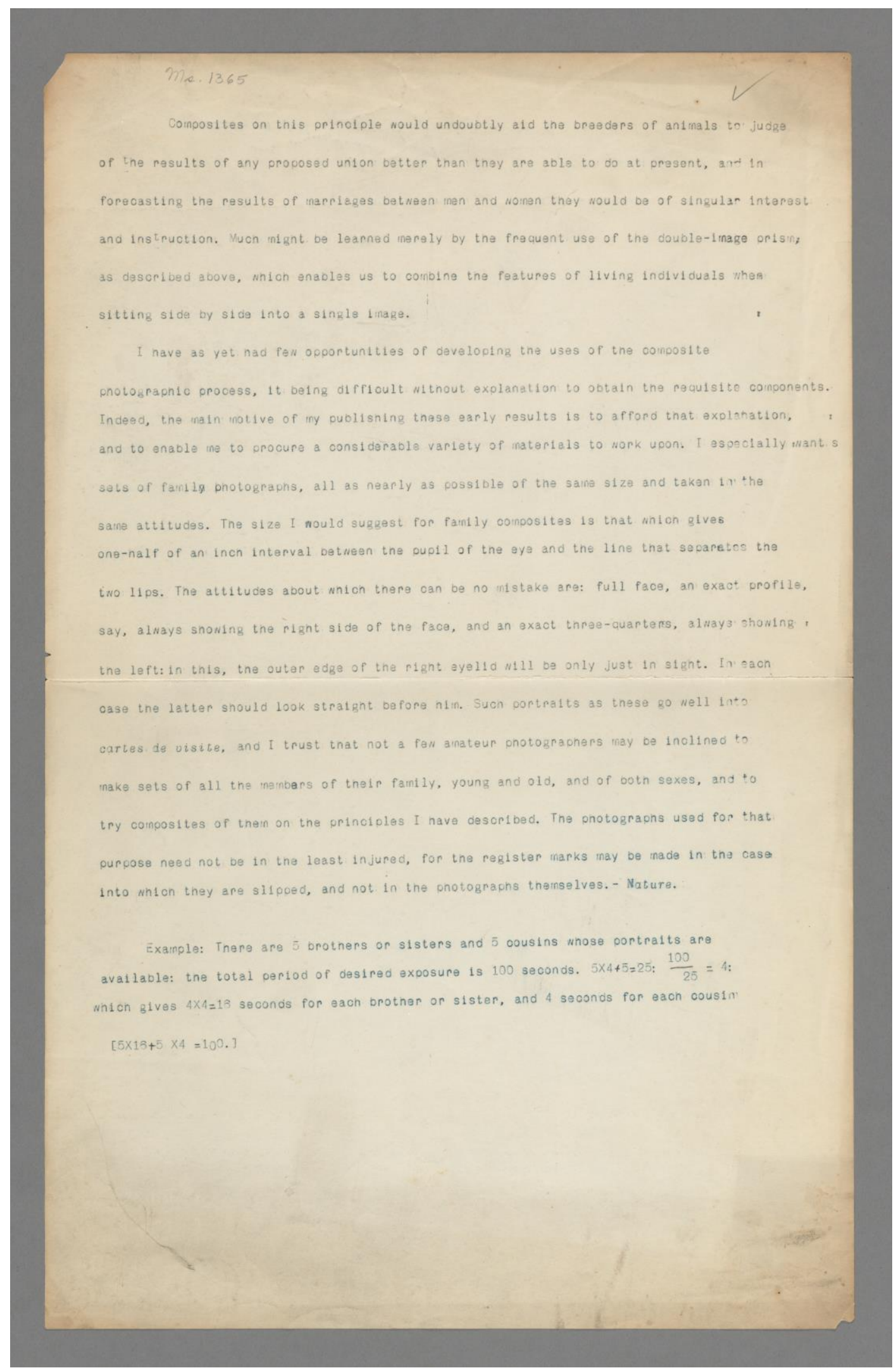

Fig. 3. MS Am 1632 (1362). Undated typescript on a single, unnumbered page. The typescript is part of the Peirce Collections, but it clearly contains the final part of Galton's article on Composite Portraits, submitted and published in Nature in 1878. Houghton Library, Harvard University. 
While Galton's typescript merely offers evidence of Peirce's early exposure to Galton's early photographic experiments, an undated manuscript (fig. 4, 5 and 6$)^{62}$ seems to offer a few more details of Peirce's own views about the technicalities of the composite process itself. The manuscript is entitled "The World of Science", and it may be part of a slightly larger project on leading ideas in the nineteenth century which occupied Peirce in the early 1900s. It contains only a brief extract of a planned comparative study of "two leaders in science who have drunk to the fountain of perpetual youth" $^{63}$ : Kelvin and Galton. Peirce colourfully describes Kelvin as "a typical boy, though 82 years old" and states that Galton is two years older than Kelvin. The reference seems to suggest that the manuscript should be dated around 1906, long after Peirce's first encounter with Galton's composite photography. Yet, the tone with which Peirce describes Galton's "latest invention" clearly betrays a persistent enthusiasm with the composite process itself. The characterisation that Peirce gives of the process, however, also suggests that he had slightly different priorities for the possibilities that Galton's method might afford:

"[Galton's] latest invention is an instrument to photograph degrees of resemblance, though this only vaguely expresses what it measures. Two objects, say two photographic portraits, are brought to the same apparent size by an optical contrivance, and are then both removed to such a distance that they become mistakable, each for the other, when the angle each subtends (or the tangent of it) is read off from a scale". ${ }^{64}$

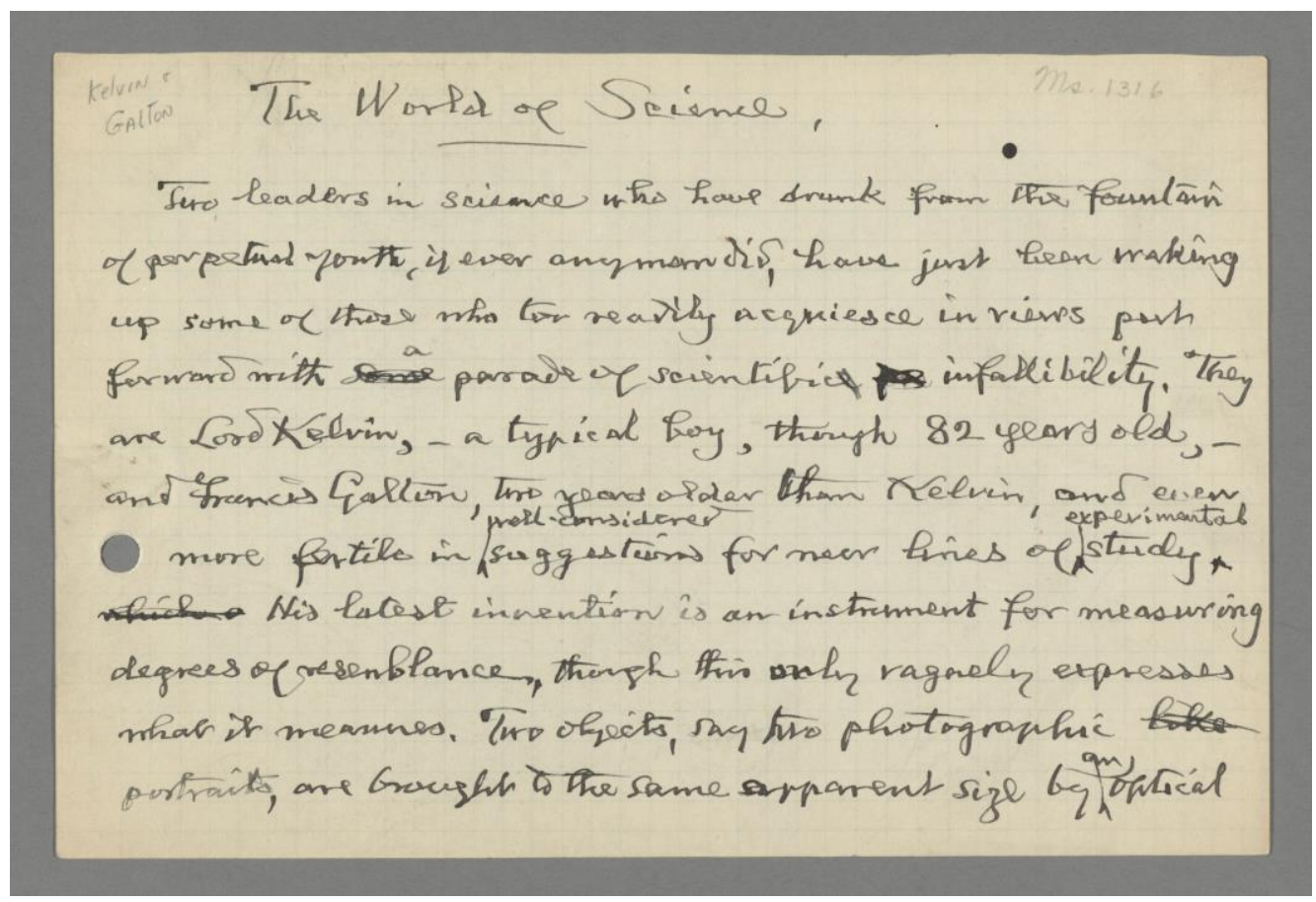

Fig. 4. C.S.Peirce, MS Am 1632 (1316), "The World of Science" (c1906), p. 1. Houghton Library, Harvard University.

\footnotetext{
${ }^{62}$ Peirce, The World of Science, MS 1316, undated manuscript.

${ }^{63}$ Peirce, MS 1316, p. 1.

${ }^{64}$ Peirce, MS 1316, pp. 1-2.
} 
Secince

3 contrivance, and are then both removed to fuch a destance that they fecome mistak able, each for the other, shen the angle each subten st (ova tangent of it) is read off on a séale. In recorching the resuler, the kind of mistakcability mas aldo be set doun; for by "mistakability" is woh meant absohte indistingrish ability, bast is the obatver's judgment that certain definite alterations wereldrender them

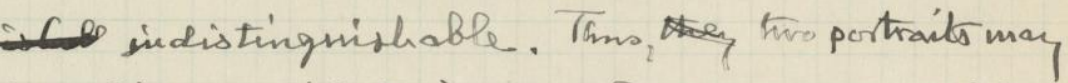
srem gist alike exceph for dread and puse; or grist alike eeceph for age; or evept for sex, ete. \$ These judgments * are noth very greatly appectes by the observer's persirnal pecentiarritess. "Resemblance", on the otter hanis, is more a question of the oheervers state ofmint than of the

Fig. 5. C.S.Peirce, MS Am 1632 (1316), "The World of Science” (c1906), p. 2. Houghton Library, Harvard University.

Seuince/fikeness of the ofjects comparef, The prycholagecal lans of sesemblance are in pressinp need of in restigation; and paltons new instrument rrist be an important air in this inguiry.

Kelein reappeared upan the scene in a character which has ahrays teen a favorite role mith huin that of a sharp evinic of the reaserring of physicists. Thistime he aftacks the entire Gody of physicists, unless he has a fers silont surpertors sho are as scepticial os himself in regars to the transmutation, of on tion or decmposition, by whech helims has, in the general judgment, Leer provel to result from the element, radium, witherut

Fig. 6. C.S.Peirce, MS Am 1632 (1316), "The World of Science" (c1906), p. 3. Houghton Library, Harvard University. 
It is rather illuminating to see that Peirce's primary attribution to Galton's composite process is that it photographs "degrees of resemblance". Not generality, not ideal types, but degrees of resemblance between photographic portraits that are manipulated specifically to be made "mistakable each for the other". What characterises Peirce's account of Galton's photographic process is the persistent emphasis on human intervention on the photographs, as well as on the preparatory materials required to obtain the portraits. Peirce's perceptive understanding of the composite process allows him to take as his main point of departure the fact that "real generalisations" are not, and cannot be, a result of the photographic process itself. They are instead the product of practical operations and controlled interventions, the very same interventions that characterise the performance of any kind of measurement. Peirce continues, becoming even more explicit on what is involved in the process:

"In recording the result, the kind of mistakability must also be set down, for by 'mistakability' is not meant absolute indistinguishability, but is the observer's judgment that certain definite alterations would render them indistinguishable. Thus, two portraits may seem just alike except for dress and pose; or just alike except for age; or except for sex etc. These judgments are not very greatly affected by the observer's peculiarities. 'Resemblance', on the other hand, is more a question of the observer's state of mind than of the likenesses of the objects compared. The psychological laws of resemblance are in pressing need of investigation; and Galton's new instrument will be an important aid in this inquiry". ${ }^{65}$

Peirce's short piece on Galton sadly stops here, but there is much that can be extracted from this last passage. If there is anything inherently objective in the photographic process, it is just in the active intervention of an observer's judgment, Peirce claims. In sharp contrast to Galton's enthusiastic acceptance of the kind of precision afforded by the camera and by the composite process more broadly, Peirce is here claiming that the kind of measurement obtained through composite photography is ultimately made reliable by the fact that an expert observer applies his or her judgment in altering and manipulating the images. The passage is interesting because it also captures the two senses in which, according to Peirce, a mind operates behind a camera and directs its operations - a logical sense and a psychological one. Psychologically, he claims, resemblance may be subject to individual and subjective states of mind, and it is those states of mind, rather than properties inherent in the objects being compared, that determine the particular respects in which something "resembles" something else. This psychological sense of resemblance, for Peirce, is still not a reason to defer the burden of identifying genuine, or "objective" likenesses to the camera (or any measuring apparatus) altogether. Instead, the study of resemblance should be itself subject to empirical investigation, ${ }^{66}$ and indeed Galton's method could expose the sense in which we choose

\footnotetext{
${ }^{65}$ Peirce, MS 1316, pp. 2-3 (emphasis mine).

${ }^{66}$ Interestingly, in the 1880s, Peirce was himself involved in this kind of empirical investigation. A crucial connection between composite photographs and empirical psychology is the work that Peirce carried out in collaboration with Joseph Jastrow. Their collaboration resulted in the publication of the article "On Small Differences in Sensation" (originally published in the Memoirs of the National Academy of Science in 1884, and now in Writings of Charles S. Peirce: a Chronological Edition, Volume V, 1884-1886. Ed. The Peirce Edition Project. (Bloomington, Indiana, 1993), pp. 122-135. The piece, itself a classic in the history of psychology, was praised by lan Hacking as a milestone in the application of statistical methods to empirical psychology. See lan Hacking, "Telepathy: Origins of Randomization in Experimental Design", ISIS vol. 79 no. 3 (1988): 427-451, pp.
} 
particular features, adjust the perspective, pick out particular objects, and then we deem them to "resemble" others. The "laws of resemblance" to which Peirce appeals in the extract are a step toward avoiding the conflation of this particular application of Galton's method from its broader, logical implications. Indeed, from a logical point of view, Peirce appeals to an "observer's judgment" as the capacity to exercise some control over the very act of rendering two portraits mistakable, and eventually indistinguishable in some relevant respects from each other. It is this capacity of exercising control, and not the self-discipline imposed by the camera, that guarantees validity in the results and generalisations that we draw from examples of composite portraits.

In her recent work on the history of nineteenth century photography, Jennifer Tucker insightfully highlights the fact that, rhetoric of noninterventionist objectivity notwithstanding, no consensus existed among scientists and practitioners of photography over whether their particular practices should conform to it. ${ }^{67}$ In this particular respect, Peirce seems to join the crowd of dissenters that Tucker singles out in her work for not subscribing to a view of objectivity as mere mechanical reproducibility. Often credited with an interpretation of the photographic image as a mere "index" or a trace, Peirce could be easily mistaken, when read superficially, for one of the proponents of just the kind of noninterventionist objectivity that he instead rejected from the outset. True, Peirce maintains that the relation of resemblance we perceive between photographs and the objects they stand for "is due to the photographs having been produced under such circumstances that they were physically forced to correspond point to point to nature" ${ }^{68}$ In this sense, Peirce argues with explicit reference to his semiotic categories, photographs belong to the class of indices, signs that stand for their objects by virtue of a physical or causal connection. But even in referring to photography as a prime example of indexicality, Peirce clearly stresses that the photograph must be produced and interpreted as an indexical sign - it must be forced to correspond point-to-point to nature. Here "force" captures both the very nature of what Peirce considers an indexical sign - a sign that shows something about particular objects by virtue of being physically connected to those objects, like smoke for fire or a barometer reading for atmospheric pressure and the very fact that for a photograph to function in such an indexical way an explicit intervention is needed in the process.

Peirce proves in a different context that his notion of indexicality is deeply rooted in a sophisticated understanding of the photographic process. In his 1898 Short Logic, just after his discussion of judgments and assertions, he indulges in another brief digression on photography. "Even what is called an instantaneous photograph, taken with a camera", Peirce explains, "is a composite of the effects of intervals of exposure more numerous by far than the sands of the sea.

431-434. More importantly, Jastrow was one of the people with whom Peirce would have discussed the relations between statistical methods and composite photography. Two publications by Jastrow show that he was extremely well acquainted with Galton's method and with his writings on the subject: Joseph Jastrow, "Composite Portraiture", Science vol. 6 no. 134 (1885): 165-167 and Joseph Jastrow "Composite Portraiture"[Letters to the Editor], Science vol. 6, no. 139 (1885): 283. For an excellent account of the historical connections between Peirce and Galton specifically through the mediating role of the figure of Jastrow see Tullio Viola, "Pragmatism, Bistable Images, and the Serpentine Line", in Das Bildnerische Denken: Charles S. Peirce, ed. F. Engel, M. Quesner, and T. Viola (Berlin: 2012): 115-138, pp.122-130.

67 Jennifer Tucker, Nature Exposed. Photography as Eyewitness in Victorian Britain (Baltimore: 2005).

${ }^{68}$ Peirce, EP2:6. 
Take an absolute instant during the exposure, and the composite represents this among other conditions". ${ }^{69}$ This clarification is indeed a key step in the parallel between composite photographs and schemata, as it clearly provides a material, concrete basis for Peirce's dynamic reading of composite photography more broadly. All the conceptual work that Peirce does on and with photography remains rooted in his critical and practical understanding of the process of photographing itself: indeed his key point here revolves around the temporality of photography, even in the case of what would be defined as an "instantaneous" image. Peirce's characterisation should also serve as a reminder of the meaning initially attributed to instantaneous photography: in the nineteenth century instantaneity was understood as very much dependent on exposure having a beginning, a middle part and an end. ${ }^{70}$ As Phillip Prodger remarks, the term was often used in the case of studio portraiture, which initially was anything but "instantaneous": in the 1840s and 1850s it involved extremely long exposures, accompanied by various contraptions to ensure that the sitters would be absolutely still for the whole length of the photograph. This resulted in obviously contrived poses, and indeed the term "instantaneous" was used for portraits in which, exposure times notwithstanding, "such contrivances would be eliminated, and the sitter could relax". ${ }^{71}$ Peirce seems to be well aware that even the most lifelike, instantaneous image is the result of a process that unfolds temporally, and is thus itself a composite of particular conditions indexically singled out among others. The composite thus produced, Peirce states, "represents this among other conditions", ${ }^{72}$ as it happens in the case of a still of the sea with clearly defined waves that blur as they break on the seashore, or a still of an aeroplane in flight where only the propellers betray movement by appearing as an indistinct and discontinuous whir. ${ }^{73}$

One last piece of evidence, historical evidence this time, shows that Peirce's approach to photography is a profoundly critical one, which is informed by his sophisticated understanding of the technical aspects of photography as a means of measurement in science. In 1901 Peirce was asked to translate Etienne Jules Marey's History of Chronophotography for the Smithsonian Institution. Peirce's annotated translation is another of the (still unpublished ${ }^{74}$ gems of the Peirce archive at the Houghton Library, available at the moment only in manuscript form. On page 30 of the translation (see fig. 7), Peirce seems to lose his temper over some of the promises Marey anticipates in speculating about the very future of chronophotography, and in particular to its application to the science of mechanics. "Mechanics" Marey explains through Peirce's translation, "is founded on the laws of motion: laws of spaces described, of velocities, and of accelerations. The difficulties that Galileo and Atwood surmounted to determine these laws will for the future be saved in all

\footnotetext{
${ }^{69}$ Peirce, EP2, 21.

${ }^{70}$ See Phillip Prodger, Time Stands Still: Muybridge and the Instantaneous Photography Movement (Oxford: 2003), esp. chapter 2.

${ }^{71}$ Prodger, Time Stands Still, pp. 41-42.

72 Peirce, EP2, 21.

${ }^{73}$ I am grateful to Joel Snyder for this simple and clear example.

${ }^{74}$ Peirce's annotated version of the manuscript remains unpublished (Peirce, MS 1514), however the final translation of Marey did appear in the 1902 Annual Report of the Smithsonian Institution as Charles Peirce, "Translation of Etienne-Jules Marey's History of Chronophotography". Annual Report of the Board of Regents of the Smithsonian Institution for the Year Ending June 30, 1901 (Washington: 1902). I am grateful to Jaime Nubiola for this rather subtle historical clarification. It was Michael Leja who first brought this manuscript to the attention of Peirce scholars as well as historians of photography. See Michael Leja, Looking Askance, (Berkeley: 2004) p. 264 (note 78).
} 
analogous cases for those who shall employ chronophotography for the purpose" ${ }^{75}$ To this optimistic view of chronophotography, Peirce responded with a scathing note in the margin, which reads:

"This is unspeakable rot! A disgrace to an educated man... As if there ever could be an analogous situation to that of Galileo! Is the camera going to supply intelligence and genius? Does not this mark the degeneracy of France? This man is a Membre de l'Institut. This is enough for me. I want to know no more of this charlatan". ${ }^{76}$

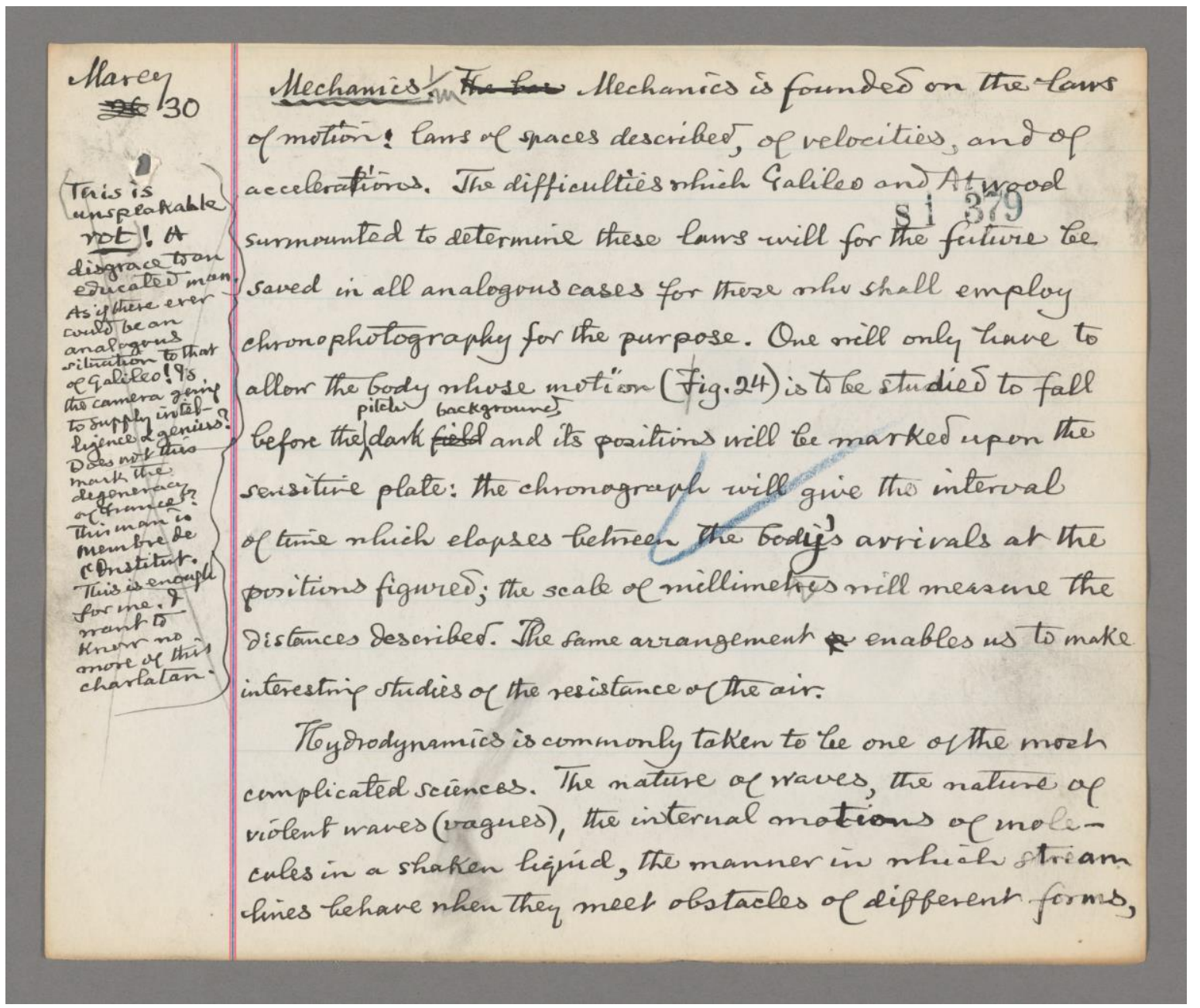

Fig. 7. Charles S. Peirce, MS Am 1632 (1514), translation of Etienne Jules Marey's History of Chronophotography (1901), p. 30. Houghton Library, Harvard University.

"Is the camera going to supply intelligence and genius?" Peirce asks. Leaving aside the current (and lively) debate over whether Marey's quote, and his work more broadly, truly provide evidence of his

\footnotetext{
${ }^{75}$ Peirce, MS 1514, p. 30.

${ }^{76}$ Peirce, MS 1514, p. 30.
} 
full commitment to a view of mechanical objectivity, ${ }^{77}$ what Peirce seems to reject here is even the remote possibility that agency might be deferred to the camera in describing the photographic process, especially when this process is used in a particular scientific context, such as the investigation of the laws of mechanics. Once again, for Peirce it is not the camera itself, but the control exercised in the critical use of the medium (as well as in the critical interpretations of its products), that renders it a reliable, and yet fallible source of knowledge. It is thus in this very different and more productive sense that photography, for Peirce, still qualifies as an objective form of representation. The meaning that Peirce attributes to objectivity - here as well as in his account of scientific inquiry more broadly - is not one of self-restraint, but one of dynamic responsibility (exercised through controlled reasoning) toward a community of inquirers, and this characterisation ultimately informs his approach to photography. ${ }^{78}$

This leads to more general conclusions about the material dimension of Peirce's use of the metaphor of composite photographs. If his theory of perception, his scattered and yet extremely perceptive thoughts on Schematism and his account of ideas sound frustrating to readers not accustomed to his style and to the depth of his philosophical ideas, it is simply because Peirce never embraced the naïve empiricism that characterised the parallels between mind and camera espoused by so many of his contemporaries. At the same time, Peirce's inquiries were not driven exclusively by abstract epistemological concerns: only a profound knowledge of the limitations of photography, along with a critical understanding of its virtues, could lead to the sophisticated and complex application of the metaphor of composite photography to such a broad range of conceptual problems. Thus, Peirce's adoption and use of the metaphor of composite photography is somehow both tailored around a practical understanding of the specificities of the medium, and around a set of conceptual conclusions that could be derived from the process of drawing broader lessons from that practice. It is this aspect of Peirce's approach to composite portraits and the supposedly objective status of photography more broadly that renders his dissenting voice particularly forceful, compelling, and definitely worthy of further scholarly investigation.

\footnotetext{
${ }^{77}$ See for example Joel Snyder's criticism of Daston and Galison's reading of Marey, in Joel Snyder, "Visualization and Visibility", in P. Galison and C. Jones (eds.), Picturing Art, Producing Science, ed. P. Galison and C. Jones (London: 1998), pp. 379-397. Snyder's article is a response to Laorraine Daston and Peter Galison, "The Image of Objectivity", Representations vol. 40 (1992), 81-128. Where Daston and Galison see Marey as a distinctive example of the rhetoric and application of noninterventionist objectivity, Snyder argues that in his work a series of displacements take place, so that agency cannot simply be deferred to the operations of the camera alone. Ultimately, in Snyder's account, the camera becomes for Marey an instrument that enhances visualisation by generating phenomena that would remain otherwise unseen, and as such it crucially involves intervention on the photographic display and in the photographic process itself. This reading is endorsed also by Ellenbogen, "Camera and Mind", whose account of Marey's method takes Peirce's comments on Marey's translation as its very starting point.

${ }^{78}$ I model this account on Joseph Ransdell's characterisation of scientific objectivity in Peirce: "Objectivity", Ransdell claims, "is not a matter of results or even of types of inferential procedures, but rather a matter of the recognition in one's communication with other inquirers that where one started from, and how one got to the conclusion (or how one thinks one can get to the conclusion), may be capable of being corrected by them, and hence to be shared so that they can be subjected to the real possibility of such correction". Joseph Ransdell, "Semiotic Objectivity", Semiotica, vol. 26, no. 3/4 (1979), p. 264.
} 


\section{Conclusions}

I began this discussion with Allan Sekula's thought-provoking "The Body and the Archive", and it is to that article that I want to return in drawing my conclusions. In closing his discussion of Galton's composite portraits, Sekula draws an interesting parallel with the American photographer and founder of the Photo-Secession movement Alfred Stieglitz:

"Both Galton and Stieglitz wanted something more than a mere trace, something that would match or surpass the abstract capabilities of the imaginative or generalising intellect. In both cases, meaning that was fervently believed to emerge from the 'organic' character of the sign was in fact certified by a hidden framing convention". ${ }^{79}$

Here Sekula implicitly refers to Stieglitz's provocative statement that in photography "beauty is the universal seen". ${ }^{80}$ What Sekula stresses, correctly in my view, is that Galton and Stieglitz's quest for generality (or universality, in Stieglitz's terms) is attained only through the hidden work of particular framing conventions, and therefore is only partly dependent on the "organic" properties of the photograph itself (or the "mechanical" properties of the photographic process). However, here is where the parallels between them end, and where a more productive comparison can be drawn between Stieglitz and Peirce instead. I showed elsewhere ${ }^{81}$ that in Stieglitz's case it is not just framing convention, but the very trained eye of the photographer-seer that allows the grasp of generality. Photography has the potential of disclosing generalities - indeed what it reveals, for Stieglitz, is a unique concordance between particular experienced events and universal forms. But a closer look at Stieglitz's practice and writings discloses the fact that this concordance for him reveals itself only when seen through the trained eye of an expert observer. Pace Sekula, Stieglitz never subscribed to the idea of generalisations independently of a generalising intellect. In this respect, his awareness that photography inevitably involves an explicit act of judgment is much closer (albeit less philosophically articulated) to Peirce's views than to Galton's. True, a set of framing conventions clearly govern Galton's portraits - and as I showed throughout my discussion he was not shy of making this as explicit as possible - but such conventions were seen as participating in the pursuit of a higher aim: the attainment of "real generalisations". Thus, intervening in the alignment, scaling and positioning of the photographs, when turned into an explicit protocol, became for Galton merely functional to the final goal of seeing the "typical" emerge right at the centre of his portraits. Galton embraced the empiricist dream of aspiring to generalisations independently of a (limited) generalising intellect in a way that finds no correspondence with Stieglitz's views, and that, as I hope to have showed in the course of my discussion, starts from opposite material and philosophical premises when compared to Peirce as well.

Peirce, on the other hand, wanted more than this from his metaphor. Deeply aware that the material process involved in photography irremediably involved an act of intervention and

\footnotetext{
${ }^{79}$ Sekula, "The Body and the Archive", p. 55.

${ }^{80}$ Frank, Waldo D., Lewis Mumford, Dorothy Norman and Harold Rugg Frank, America and Alfred Stieglitz. A Collective Portrait, (New York, 1934), p. 132.

${ }^{81}$ Chiara Ambrosio, "Beauty is the Universal Seen: Objectivity as Trained Vision in Alfred Stieglitz's Experimental Aesthetics”, Visual Studies vol. 29, no.3 (2014), pp. 250-260.
} 
judgement, he proceeded to investigate how a renewed awareness of these material circumstances could enrich - rather than hinder - a critical and philosophical use of photography to investigate our cognitive abilities. Thus the power of the camera, in his account, did not reside in providing an objective mediation that would make up for the limitations of our capacity to generalise. On the contrary, what some of his contemporaries would have considered as glaring limitations in the photographic process itself (the fact that agency can never be fully deferred to the instrument itself) were for Peirce the very reasons of its applicability as a conceptual metaphor in the first instance. Construed as a genuine form of mediation, mediation conceived in semiotic terms and incorporating the capacity to produce, interpret and extend the range of our fallible and yet reliable generalisations, photography became for Peirce a conceptual tool to investigate the very strengths of our (equally fallible, and yet still reliable) powers of judgment. 